\title{
Constructing a Global Centre for Competence from Local Knowledge: The Case of Pirmasens
}

\author{
Eike W. Schamp \\ Eike W. Schamp, Department of Human Geography, Goethe University of Frankfurt/M., Germany \\ (schamp@em.uni-frankfurt.de)
}

\begin{abstract}
Mature industrial districts generally appear to suffer from a steady reduction of their technological competences and competitiveness. However, the long period of decline also offers an opportunity for countervailing policies. Using the ageing footwear district of Pirmasens (Germany) as an example, this paper discusses learning processes in rejuvenating the competence base of the industry. After several decades of continuous decline, a new competence base was launched around the establishment of the International Shoe Competence Centre ISC. The paper firstly discusses the adaption of the concept of "competence", a tool used in regional high tech policies, to the low tech, traditional and cross-sectoral shoe production system. Secondly, the paper considers the special historical conditions which enabled local and non-local actors to ensure the success of policies based on rejuvenated "traditional" competences. External shocks which simultaneously deepened crises and provided opportunities include the breakdown of the socialist system, the unification of Germany and the erosion of the regional economic prosperity as a result of the withdrawal of American troops from their main base in Germany. Constructing the centre for competence was in itself a cumulative and path-creating process. It is, however, more beneficial to globalized shoe companies than to the region.
\end{abstract}

Keywords: local knowledge, renewal of industrial district, traditional industries, local initiatives

\section{Introduction}

Footwear production in old industrialized economies is considered to be a mature, lowtech industry which can only survive in small niches given the tremendous competitive pressure from low wage countries. Mature footwear districts have come to the end of their life cycle and seem to be destined to disappear. However, the rather scanty literature on mature districts paints another picture. In both Italy (Zuchella 2006) and Spain (Belso-Martinez 2008), mature footwear districts are succeeding with rejuvenating strategies based on a mix of integration into global value chains, outsourcing and learning new competences.

However, the downturn of a mature district can last several decades before a district fully disappears. Thus, there is time for learning and policy-making in order to rejuvenate the competences of the district. Policy issues then include identifying which expertise should be strengthened or acquired, which measures should be taken when and by whom to stop the path-dependent downward turn and recreate an upward trajectory in the region.

The last German footwear district of Pirmasens is a case in point, as recent policies attempt to enhance existing expertise in order to supplement the old production base with a competence-based sectoral service centre. Will this cluster be able to revive, as a 'phoenix from the ashes' (Tödtling and Trippl 2004)? How can a given pathdependent 'competence' which will apparently inevitably lead to the decline and death 
of the district, be reshaped into a rejuvenated technological path (Martin and Sunley 2006), for either local or non-local industries and trade? This paper will discuss a new policy approach to making use of 'traditional' competences and adding new ones which are mostly intended to enhance employees' skills in order to upgrade both manufacturing activities and trading in footwear. In 2008, an International Shoe Competence Centre (ISCC) was established which is expected to serve as the focal engine for companies to learn and acquire competences, first in the German footwear industry, followed by the large German footwear retail companies and, finally, abroad. Although ideas for change have long been mooted in the district, a long period of debate and a major crisis in the region's economy were necessary before some actors, from both the private sector and public authorities, were prepared to network and successfully raised financial support for change from the state. This was and still is a highly disputed policy instrument, not least because it has created forms of inclusion and exclusion within the district.

In the first section, I will briefly describe the creeping decline of traditional technological competences in the district over the last four decades and identify some attempts to counteract these losses. Although it is a 'fuzzy' concept, regional competence has become a new focus in regional innovation policy in Germany. What is different in the Pirmasens case will be discussed in the second section. In the main part of the paper, I will examine the implementation of the ISCC as an evolutionary process shaped both by an unexpected (major) event and increasing returns or path-dependent policy decisions. If it is successful, Pirmasens will develop into a global centre of competence for international footwear companies and not return to a lively, rejuvenated local industrial district.

The paper is based on a number of personal interviews conducted in spring 2006, firstly, with local actors who were directly involved in the implementation of the ISCC, such as managers of large footwear companies and a local non-profit research centre, members of intermediary organizations such as the chamber of commerce, industry association and trade union, and the mayor of the city of Pirmasens. Secondly, ten entrepreneurs in the local footwear and footwear supplier industry who were not involved were also interviewed. Finally, recent information has been gathered through several telephone interviews with intermediaries in 2008 and 2009 and document analysis. This has benefited from continuing research on the district as a number of fairly regular surveys of the footwear industry were carried out in the Pirmasens area in 1998, 2000 and 2003 (Bertram and Schamp 1999, Schamp 2005).

\section{The Deteriorating Technological Base of the Ageing District}

The footwear industry has long vanished from many regions in Germany. The Pirmasens district, however, survived but became a shadow of itself. Pirmasens is situated in a remote area at the German-French border (Figure 1). Most companies there produce women's footwear for the German-speaking market in a very specific midquality sector, i.e. the 'comfort shoe'. This district is distinct from others in several respects. Firstly, while the number of firms today is quite small, average firm size is larger than in most other districts, particularly in Italy and Spain. Secondly, it has a fairly long history as the district dates back to the end of the nineteenth century. Thirdly, from its beginnings it developed into a production system with extreme vertical depth including not only a host of heterogeneous suppliers in parts production and services but giving rise to a sophisticated footwear machinery industry as well as a chemical 
industry (adhesives). Additionally, wholesale and retail trading companies emerged in large numbers. Technical innovation mainly stemmed from new machinery, new materials and - later - from new information technologies. Thus, related industries often brought innovation into the footwear assembly industry. Innovation was mainly based on learning by (local) interaction and by doing, when local assemblers cooperated with engineering companies in adapting machinery, and engineering companies could profit from tests in the daily production practice of an assembler's factory. As a consequence, a 'tacit' local learning system for more or less incremental technical innovation developed in the district.

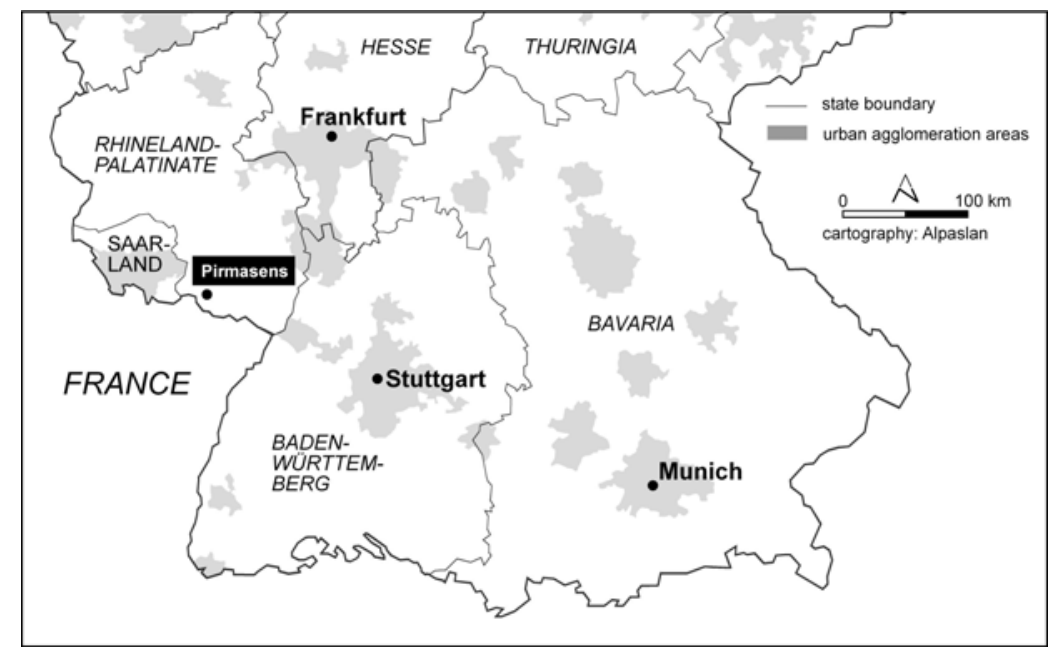

Figure 1: Location of Pirmasens in South West Germany

This local knowledge system certainly is a stylized fact as more radical impacts for innovation came from external sources, sometimes from abroad. Nevertheless, it is possible to claim that this deep knowledge system laid the foundations for the long survival and slow decline of the district, compared to other footwear production locations in Germany. This strength has diminished since the end of the 1960s. Between 1960, 1999 and 2008 employment in the city's footwear sector declined from 10,000 to 2,000 and 1,000, respectively, in nowadays less than ten assemblers. While most of the surviving footwear assemblers outsourced either labour intensive production or full assembly to low wage countries, many parts producers shifted to new markets, in particular to the growing automotive sector (Figure 2). A downwards spiral developed, undermining the district's functional cohesion and reducing its employment capacities. As a result, the traditional local knowledge system was increasingly eroded by the functional dissolution of the district.

Various instruments intended to enhance the competence base of the district have failed. Skill formation supported by what is now the only vocational school for footwear production in Germany (founded in 1927), attracted declining numbers of pupils after the 1960s. In the late 1980s, the state government relocated the faculty of footwear technology, part of Kaiserslautern polytechnic, to Pirmasens. However, like the vocational school, it acquired a poor reputation among the medium-sized and large companies and was accused of inadequately teaching the current special practices of the sector. By the mid-1990s, the faculty was faced with closure due to low student demand. Finally, the test lab PFI (Prüf- und Forschungsinstitut) that had been founded 
by the association of German footwear companies in 1956 as a non-profit service institution, remained for a long time tied to the declining trajectory of the footwear sector.

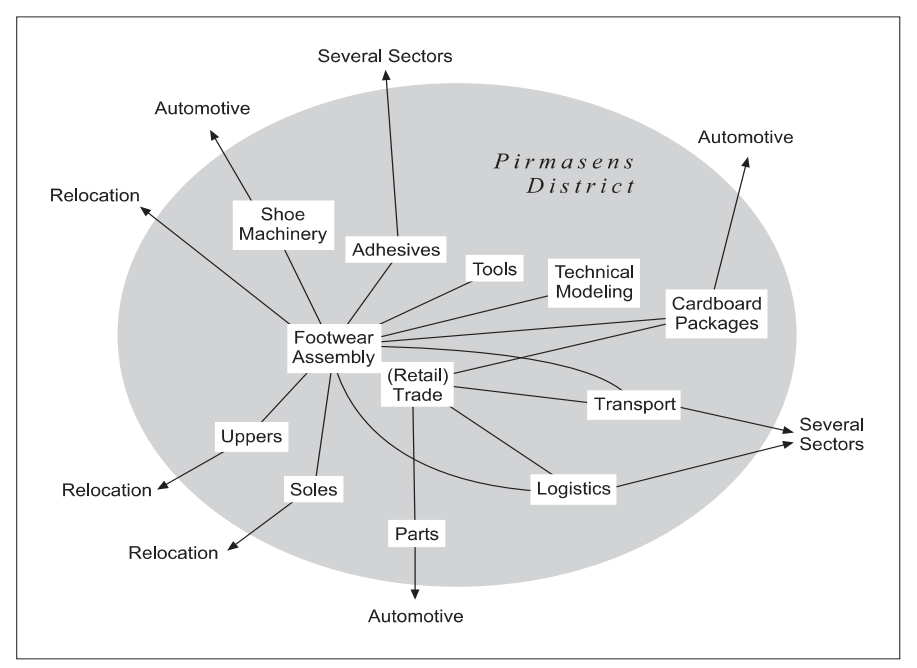

Figure 2: The Move of Footwear Suppliers to Other Sectors

However, surviving footwear companies, internationalized footwear assemblers and large traders who had emerged in other parts of Germany increasingly required new competences in their labour force and hence new forms of training and education. Footwear assemblers, in particular, now need a well trained middle management, combining the technical skills of the sector with education in marketing, design, and plant management. In fact, as parts production and even assembly have been outsourced to foreign plants or subcontractors, the remaining companies have shifted their competences from mere technology to design, branding and distribution. Improving fashion design, launching new collections, controlling production, testing product quality and organising the distribution of shoes have become major functions in the modern 'hollow' footwear company which has outsourced all of its production processes abroad.

For a long time, local intermediary organizations and some large non-local companies have expressed great concern about the breakdown of Pirmasens' traditional image as a classical production location for the German footwear market, for different reasons. While local political and administrative actors were interested in safeguarding local employment and tax revenues, large German footwear companies - through the footwear producer's association - increasingly raised the problem of gaining and training qualified personnel for their middle management in domestic and foreign plants. So collective action seemed to be at stake for the renewal of the competence base. In fact, according to the literature, industrial districts are successful if they have sufficient social capital which means, in other words, that companies and intermediary organizations are prepared for networking. This, however, is a weakness of the region.

\section{Competence - a Fuzzy Concept for Regional Policy}

The notion of competence is rather 'elusive', according to Cohendet et al. (1999), and needs further differentiation: "Competence emerges through the learning process of the 
firm and requires a conjunction of different knowledge and skills” (228). This is the micro-economic view of business sciences, based on the theory of the firm and its followers (Foss and Mahnke 2000, Amin and Cohendet 2004). Although many authors still complain of a lack of clear definition in these approaches, they clearly point to the internal resources of the firm as factors as relevant to the firm's competitiveness: size, financial power, management skills, and innovativeness, which can all be seen as resulting from the firm's history.

Lawson (1999) sees the learning of new competences as the result of a firm's internal processes and its external interactions, often based on the advantages of geographical and organizational proximities. We will not discuss different notions of regional competence in detail as they have evolved in neo-Schumpeterian and evolutionary approaches. Suffice to say that, in Germany, the notion of competence has been more attractive for regionalized research policy than for regional policy proper and has therefore been mainly discussed in high-tech policies. Research policy is mainly the domain of the Federal State while regional policy is a responsibility of the individual states (Länder). Research policies have increasingly focused on establishing centres and networks of competence. An early study for the Federal Research Ministry described a "competence centre in the broadest sense as [...] a regional agglomeration that manages to create added value through a well networked 'value chain' ranging from knowledge creation to commercialization and diffusion, in one or more technology based markets" (Boekholt et al. 1998: 3). While competence-oriented policies first focused on creating and using geographical proximity of technologically related firms, current German research policy no longer emphasizes the need to create local networks, but aims at promoting radical innovation in cross-sectoral technologies.

There is no specific promotion of innovation in a given product (shoes) or sector (footwear industry). Thus this high-tech oriented understanding of competence on the part of both political agents and scientists in economics and economic policy is obviously misleading with regard to footwear production. Here, small and medium sized firms with weak internal resources predominate, and knowledge is not created through interaction with large research organizations but in daily practice with suppliers and clients. The notion of innovation in public innovation policy has been criticized from several perspectives (Hirsch-Kreinsen et al. 2005), including the tendency to view it one-sidedly as a technical process, thus underestimating the effects of newness in organization and design which are so important for the economy today. Both play an increasing role in the competitiveness of the footwear industry. The question remains as to whether measures of regional policy based upon a 'false' understanding of the current concept of regional competence can be successfully implemented for rejuvenating and upgrading a mature district into a service centre.

\section{Improving the Competence Base}

Improving or altering the deteriorating competence base of a local production system may be a difficult task for regional policy. 'Reinventing' Pirmasens as a technological competence centre of global importance for all kind of activities related to footwear, means drawing in new actors, recreating a technology path, acquiring new sources of finance, and implementing a new vision. History matters, as historical events open up challenges and opportunities for actors, visions and policies develop over time, and the emergence of a new technological local path dependence is the result of intended action 
and unintended consequences. The following section thus takes an evolutionary perspective on the recreation of competences at the district's location, Pirmasens.

Underlying recent political efforts is the crisis of the regional economy in the 1990s, which came on top of a long-term downward turn in the declining footwear industry since the 1970s, the region's first economic base. The unexpected events of the fall of the Berlin wall and German unification in 1989 caused a fundamental crisis in the region's economy. As a result of these political changes, the region lost its importance as a major base for American troops in Europe. In the mid-1990s, American military withdrew from the region and laid off their German civilian employees, quite suddenly deflating the region's second economic base.

An extended multi-layered process of political support for 'conversion' came into being and was used successfully by local agents. Federal and state governments raised large sums in so-called conversion programmes for regions hit by the closure of military estates, affected by environmental pollution from military uses and the layingoff of civilian employees and those responsible for the management of vast areas of real estate affecting (urban) planning and property markets. In certain areas such as the Pirmasens region, policy agents could add public monies from European funds, mainly from the regional fund (e.g., 12 per cent of total regional funding or 107 million $€$ between 1998 and 2003). Creativity on the part of local policy makers with regard to fund-raising, their ability to initiate new concepts for public and private cooperation in development (required by the state (Land) government as a prerequisite for financial support), and networking at all levels and in all directions were essential ingredients of an ultimately successful policy to unlock new options for the region. It appears that cooperation between local agents such as the city's mayor (a member of the Christian Democratic Party CDU) and local entrepreneurs, and non-local actors such as the Rhineland-Palatinate state government (Social Democratic Party SPD) and the German footwear association HDS directed much money into the region for conversion. Some of this money was used to follow a new concept which emerged during the 1990s, i.e. to (re-)create Pirmasens as a major centre for footwear technology.

\section{Table 1: The Four Pillars of the ISCC Concept}

1. An internet-based knowledge management system on footwear and leather knowledge, covering information on personnel, experts, machinery and materials, certificates and norms, and events in the sector. Income will be generated not only from information services but also from advertising.

2. Applied research and development in close collaboration with the PFI and the UAS.

3. Attractive and practically-oriented training courses and further education programmes for the international footwear industry as the ISCC's main target, jointly implemented by the ISCC, the UAS and the vocational school.

4. A model factory as a central instrument to achieve the goals in R\&D and in training and education. It currently forms the core of the technological capacity of the ISCC.

Thus, the basic vision had already been developed and some initial investments already implemented when it came to realizing the idea of a world shoe competence centre. In June 2008, the International Shoe Competence Centre ISCC opened its doors. It offers services to the sector in a diverse range of activities and is expected to be an international beacon of the German footwear industry's 'competence', whatever that may mean (Table 1). A former military barracks complex was designated to become the site of technological competence. The PFI institute was relocated from the city centre, as was the footwear technology faculty from an old industrial site. New concepts could 
be implemented based on new equipment in new buildings, and this lead to expansion. PFI provided new services to new markets, increased employment and became highly profitable within short time. The University of Applied Science (UAS) added new faculties in textile technology, plastic materials, chemistry and logistics and saw the number of students increase.

The ISCC's concept obviously does not correspond to current technology policy. Firstly, it focuses on full technological support in the sense of services of all kinds to a given sector. Secondly, it presumably achieves incremental innovation only, and thirdly, it is orientated towards international companies which are not necessarily located in Pirmasens and whose value adding activities are largely located abroad. Thus, while the idea of revitalising the district's technological competence and adding new competence to an ageing industrial district refers to the context of an extensive technology policy in Germany, where notions such as competence, competence centre and competence network form the core of a public debate, it wholly contradicts the underlying text in regional policy of innovativity in high tech fields by means of which high quality work places and high added value can be achieved. It is an interesting transfer of a concept combining a modern public vision of the 'research and high-tech competence' of the German economy with a legitimizing image of the 'traditional technological competence' of a district.

A closer look at the different promoters of the ISCC will deepen our understanding of how far and in what way the ISCC can contribute to the rejuvenation of the mature footwear district and Pirmasens' regional prosperity. The idea was born in a circle of local managers from large footwear companies with international activities and was supported politically by the mayor of Pirmasens early on. Both have diverging interests. Large German footwear producers dominate the association of footwear producers (HDS), located in Offenbach near Frankfurt. Whether they are in the district or not, they have mostly relocated their production abroad. Whether in Pirmasens or elsewhere, they are aware of an urgent demand for the education and training of middle managers for foreign plants. Compared to other sectors, footwear companies are small and medium-sized companies which do not train staff on their own. When obliged to employ foreign managers they realize that the particular culture of a German mediumsized company (Mittelstand) is barely understood. As a consequence, their main desire is for modern facilities for training and education. Here, they meet with requirements from the increasingly competing association of huge trade companies in footwear as the boundaries between producer and trader become blurred with the trend towards the 'hollow' footwear corporation. It is the organization of training and education that matters and not its location. Thus, different models have been discussed, including the relocation of the ISCC to Offenbach, near the association's headquarters. However, neither the association nor the large companies were prepared to invest large sums in the project (which finally amounted to six million $€$ ). By raising local support from the mayor, local managers at Pirmasens were finally able to offer an opportunity for its implementation. The key issue was to find funding.

The mayor as the representative of local interests had different motives for supporting the idea, but no budget. He is the mayor of a shrinking city, in terms of both economy and population, located in a shrinking region. Pirmasens benefited from the cold war when the region became the strongest military base for American troops in Europe. The creeping decline of industry since the 1970s and the final withdrawal of the American troops in the 1990s following German unification had a marked negative 
effect on the local and regional economy. The level of employment is constantly falling, while the population is ageing and continuously shrinking. Thus the city aims to preserve and continuously develop the surviving elements of its formerly important economic base, utilising the still prevalent image of Pirmasens as 'the' footwear city in Germany. Subsidies from the Federal Government for the conversion of military sites and the local labour market enabled the city to offer the site and one million ·) for the construction of the required buildings. This was obviously necessary as the project was in danger of failing because neither local nor non-local footwear companies were prepared to invest. In this way the city also succeeded in persuading the reluctant state government to co-invest.

In order to keep running costs low, the PFI was involved as the main organiser of the ISCC. The lab is extremely successful in providing technological consultancy and services for a range of industries in Germany and abroad. In this market, scale economies are a main driving factor of competitiveness. The dominant aim of the management is therefore to grow into new markets such as practical training, but with a reduced financial risk. This target was achieved through control of the ISCC as PFI holds 90 per cent of its shares, the footwear industry association HDS and the city of Pirmasens 5 per cent each.

These promoters who form the core of the ISCC's supporting network are augmented by further partners at the network's fringe. These are, firstly, the vocational school which was relocated to the site of the ISCC in 2009 and will become an integral part of ISCC after its planned privatisation. Secondly, the nearby UAS which has revised its curriculum and now draws on the assistance of the ISCC by holding practical courses in the nearby ISCC machinery hall. And, finally, the local branch of the trade union.

To sum up, the ISCC has become a project of the municipality and the large footwear assemblers. Most local small and medium-sized footwear companies and all the local footwear suppliers have not been included in the network. The former recently lost their political power when the local footwear industry association was integrated into the national association HDS. Some of the latter are very successful with new technologies, forming the spearhead of innovation in the traditional technological competence of the district.

\section{Conclusions: Can Political Action Revitalise the District?}

There is increasing concern about the challenges of renewing old districts and industries for public policy (Tödtling and Trippl 2004, Hassink 2007). To what extent is it possible to transform an ageing district into a learning cluster as Hassink (2005) recently suggested? And what does this imply for the welfare of the region?

This paper has shown that it takes time to form networks in a district, which is caught in a fragmentation trap (Tödtling and Trippl 2004). Neither functional necessities nor trustful behaviour exist among the surviving companies to encourage them to cooperate. There is obviously a need for a rousing event to impel policymakers and some alert entrepreneurs to push a vision ahead to develop and realize a concept for revitalisation. In the case of Pirmasens, this event was the final withdrawal of the American troops from the region in the 1990s, causing a tremendous crisis on the local labour market but creating new opportunities as the state and Federal governments responded by funding investments for 'conversion'. Ultimately, it was the ability of regional actors, from both the private and public sectors, to create visions of Pirmasens 
becoming a technology centre in footwear and the capacity to acquire financial support by making use of the multi-level political system in the European Union. Creating the technology centre was in itself a cumulative and path-creating process: firstly, by relocating and modernizing the labs of PFI, then by relocating and extending the UAS, furthermore by bringing the ISCC into being, and finally by amalgamating the vocational footwear school. This could only be realized by involving the association of German footwear industry and raising large funds from non-local authorities (state, Federal government, EU) (Figure 3).

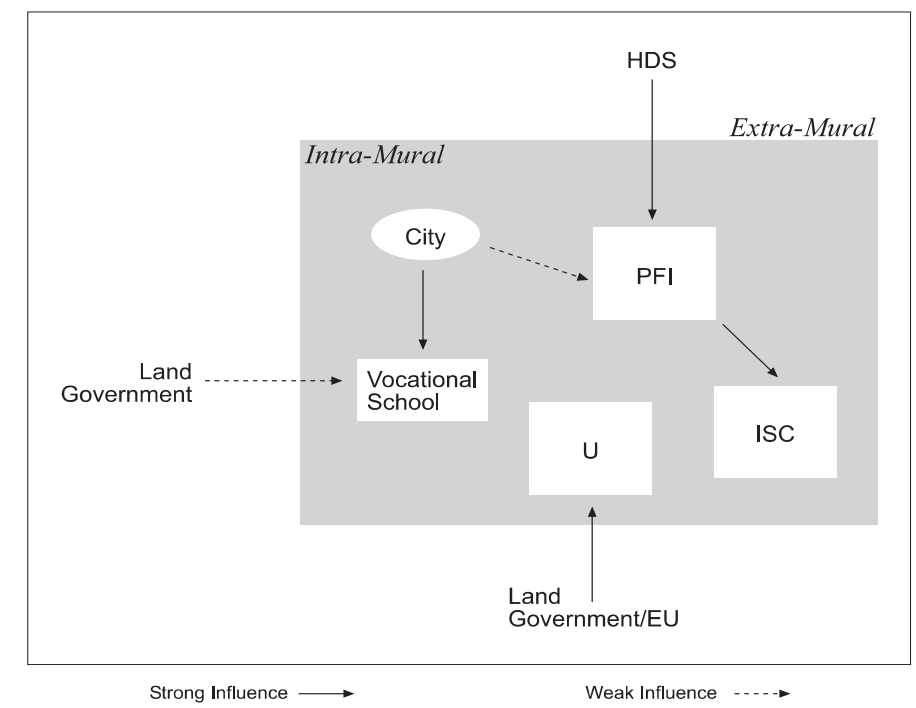

Figure 3: Stakeholders Contributing to the Creation of the Competence Centre

Many participating actors still argue that the local knowledge 'around the shoe' that still exists despite of the shrinking of the industry, and the stock of local organizations in the footwear industry, stand for the future success of the competence centre. This can be seen as an argument legitimizing the location and the investment. In fact, larger and non-local footwear producers will achieve a collective competence in qualified education and training of their middle management. Large traders, among them Europe's largest shoe trading company Deichmann, make use of the ISCC to enhance their workforce's technological knowledge in order to improve sales practices for higher quality shoes. ISCC has recently opened up a branch in Ethiopia for the improvement of local leather production and local footwear production; once again an investment in favour of international companies from Germany, as Ethiopia is the world leader in goat and sheep leather production.

Thus, we can conclude that the ISCC has successfully begun to become the focal place for upgrading the footwear business in Germany. The competence centre is, however, more closely bound to fostering skills than (technological) innovation. Some local spillovers may occur such as the recent foundation of a number of new footwear companies. But unlike the evidence in Italian footwear districts (according to Zuchella 2006), companies 'around the shoe' will never return to form the principal economic base of the Pirmasens region. While this 'competence' centre is good for the sector, improving its overall competitiveness, it is a rather expensive tool in regional policy. 
The growing self-confidence of many actors in the region will be outweighed by a fairy small improvement on the local labour market.

\section{References}

Amin, A. and Cohendet, P. 2004. Architectures of Knowledge, Firms, Capabilities, and Communities. Oxford: Oxford University Press.

Belso-Martinez, J.A. 2008. Differences in survival strategies among footwear industrial districts: The role of international outsourcing. European Planning Studies, 16(9), 1229-1248.

Bertram, H. and Schamp, E. W. 1999. Deindustrialisation, restructuring and exit strategies of firms in ageing industrial districts: The case of footwear and leather goods industries in Germany, compared, in Demography of Firms, Spatial Dynamics of Firm Behaviour, edited by J. Van Dijk and P. Pellenbarg, 67-86.

Boekholt, P. et al. 1998. Technopolis. An International Comparative Study on Initiatives to Build, Develop and Support 'Kompetenzzentren'. Endreport Available online at: http://www.bmft.de [accessed: 10 March 2006].

Cohendet, P., Kern, Fr., Mehmanpazir, B. and Munier, Fr. 1999. Knowledge coordination, competence creation and integrated networks in globalised firms. Cambridge Journal of Economics, 23, 225-241.

Foss, N. and Mahnke, V. (eds.). (2000). Competence, Governance, and Entrepreneurship. Oxford: Oxford University Press.

Hassink, R. 2005. How to unlock regional economies from path dependency? From learning region to learning cluster. European Planning Studies, 13, 521-535.

Hassink, R. (2007). The strength of weak lock-ins: The renewal of the Westmünsterland textile industry. Environment and Planning A, 39, 1147-1165.

Hirsch-Kreinsen, H., Jacobson, D. and Laestadius, St. (eds.) 2005. Low-tech Innovation in the Knowledge Economy. Frankfurt/M.: Peter Lang.

Lawson, C. 1999. Towards a competence theory of the region. Cambridge Journal of Economics, 23, 151-166.

Martin, R. and Sunley, P. 2006. Path dependence and regional economic evolution. Journal of Economic Geography, 6(4), 395-437.

Schamp, E.W. 2005. Decline of the district, renewal of firms: An evolutionary approach to footwear production in the Pirmasens area, Germany. Environment and Planning A, 37, 617-634.

Tödtling, F. and Trippl, M. 2004. Like phoenix from the ashes? The renewal of clusters in old industrial areas. Urban Studies, 41(5/6), 1175-1195.

Zuchella, A. 2006. Local cluster dynamics: Trajectories of mature industrial districts between decline and multiple embeddedness. Journal of Institutional Economics, 2(1), 21-44. 